\title{
The
}

Roy Adaptation

Model in Action 
The Roy Adaptation Model in Action

J. AKINSANYA, G. COX, C. CROUCH

AND L. FLETCHER

Orem's Model in Action

s. CAVANAGH

The Riehl Interaction Model in Action

B. KERSHAW AND B. PRICE

The Roper-Logan-Tierney Model in Action

C. NEWTON

Peplau's Model in Action

H. SIMPSON 


\section{The \\ Roy Adaptation \\ Model in Action}

JUSTUS AKINSANYA

BSc, PhD, RN, ONC, BTA(Cert), RNT, FRCN, FWACN, FRSH

Pro Vice Chancellor and Dean

Anglia Polytechnic University

GREG COX

$R N, R N T, \operatorname{DipN}($ Lond), RCNT(CertEd)

Lecturer in Nursing

Anglia Polytechnic University

CAROL CROUCH

$B A, R N, R C N T, R N T($ CertEd)

Lecturer in Nursing

Anglia Polytechnic University

and

LUCY FLETCHER

$R N, \operatorname{DipN}($ Lond), RNT(CertEd(FE))

Lecturer in Nursing

University of Hertfordshire

Series Editor

BOB PRICE

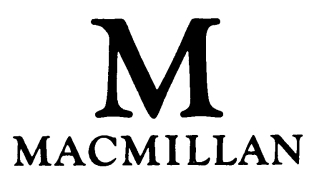


(C) Justus Akinsanya, Greg Cox, Carol Crouch and Lucy Fletcher 1994

All rights reserved. No reproduction, copy or transmission of this publication may be made without written permission.

No paragraph of this publication may be reproduced, copied or transmitted save with written permission or in accordance with the provisions of the Copyright, Designs and Patents Act 1988, or under the terms of any licence permitting limited copying issued by the Copyright Licensing Agency, 90 Tottenham Court Road, London W1P 9HE.

Any person who does any unauthorised act in relation to this publication may be liable to criminal prosecution and civil claims for damages.

First published 1994 by THE MACMILLAN PRESS LTD

Houndmills, Basingstoke, Hampshire RG21 2XS and London

Companies and representatives throughout the world

ISBN 978-0-333-57414-0

ISBN 978-1-349-12896-9 (eBook)

DOI 10.1007/978-1-349-12896-9

A catalogue record for this book is available from the British Library 
Foreword

vii

Preface

Acknowledgements

\section{General introduction}

(Justus Akinsanya) 1

Development of theories of nursing 3

Theory, theoretical frameworks and conceptual models 4

Roy and the elements of nursing models 5

Purpose of nursing theories and models $\quad 6$

Nursing theories and models - implications

for practice, education and research 10

Summary

2 Introduction to Roy Adaptation Model (Justus Akinsanya)

Modes in Roy's Model

Concept of modes

Problems of human adaptation

Summary

3 Use of Roy Adaptation Model in practice (Justus Akinsanya)

Physiological mode

Self-concept mode

Role function mode

Interdependence mode

4 Applying the Model I (Lucy Fletcher)

June - the informal carer

Paul - overdose of paracetamol with alcohol

5 Applying the Model II (Carol Crouch)

Roy's Model - a basis for a helping relationship

Christine - a study in interdependence 
6 Applying the Model III (Greg Cox)

Applying the Adaptation Model following an emergency admission

7 Evaluation (Justus Akinsanya, Greg Cox, Carol Crouch and Lucy Fletcher

Index 
It is a privilege to introduce this volume on the Roy Adaptation Model in the series Nursing Models in Action. To link conceptual developments with nursing practice provides such theorising with a reason for being. We think about nursing and what it means only to provide effective practice.

There is no doubt that in this endeavour, the nurse is reflective, however, as the authors have so clearly noted, it is the model that provides the guidelines for reflection. This reminds me of an incident that occurred a few years ago when I was a participant at a nursing theory conference at the Royal College of Nursing in London. As might be expected at any such conference, there were sceptics among the audience. After hours of presentations and discussions, a ray of light broke through the murkiness.

One participant shared a profound insight, 'Oh, I get it; when we were told to use the nursing process, we should have had nursing models first, to know what we are processing'. Yes, truly the nursing process is a hollow skill. It assumes that the nurse processes with the patient the assessment, planning, implementation and evaluation that is individualised nursing.

The model of nursing provides an answer to the questions, what is nursing about and therefore, what is the nurse about when doing nursing? This crucial link between the concepts of the model and how the nurse manages each patient situation is apparent throughout the chapters of this book.

The authors have demonstrated this link of models to nursing practice in repeated real clinical situations. This provides a real service for believers and sceptics alike.

A second fundamental issue to which the authors contribute some clarity is the question of the use of theories and models in curriculum development. The rationale for the place of models in nursing education is the same as that for their use in practice.

To teach about nursing, one knowingly or unknowingly takes a stance on one's beliefs and concepts of nursing. Models provide both the organising framework and direction for the detail that is taught in the classroom, the laboratory and the practice branches. A word of encouragement is warranted here. Countless faculties have debated the ponderous issues of major change. To undertake this arduous task takes commitment to both the heritage of nursing 
and to the principles one wants to operationalise. This is not a project for the faint-hearted. Yet no matter how difficult the task, your colleagues in similar endeavours can assure you that the outcome is exceedingly rewarding. The professional growth of nursing among new nurses and those working with them soon becomes obvious. Nursing does not essentially change, but rather becomes manifest and explicable.

Finally, the openness and stance of critique that the authors uphold are to be commended. The authors' concern that we maintain a critical stance in the use and study of nursing models is pivotal. Models are useful in the extent to which they guide effective nursing practice and raise further questions to be solved in practice. A closed and stylised system is not immediately receptive to new ideas because there is a tendency to reinterpret any observations to make them conform to the system [Fleck, L. (1979) Genesis and Development of a Scientific Fact, Chicago, Illinois: University of Chicago]. However, nursing knowledge develops as does all knowledge. We allow room for error because discovery is inextricably interwoven with being able to recognise a new relation. To recognise this new relation, many another relation must be denied or overlooked. We can say that the practice situation can be described in a given way by the model. But the model itself is developing and this growth may call for additional identification of new relations.

A good example that the authors note is the understanding of the regular and cognator mechanisms. These theoretical concepts are used to describe the process central to human adaptation. Using careful observations in practice, and skilful research design, the basic dynamics of this adaptive process can come to light. Nurses can identify some of the commonalities in cognator/regulator activity in patients. Differences in such activity from person to person can be studied. A much fuller science of the person awaits such detailed work.

We are pleased to have colleagues on both sides of the Atlantic working on the professional expression of nursing in education, practice and research. We hope that nursing models may provide the fullest of contribution to this effort.

Boston, Massachusetts, USA

SISTER CALLISTA ROY $R N, P h D, F A A N$ 
Whether we are referring to changes in society, professional practice, or the technological and economic challenges facing nurses and patients alike, we are all familiar with the need for 'adaptation' - at least in a passing way. Adaptation, coping, developing, thriving and growing are the parlance of everyday conversations, the concerns of parents and spouses, and the goals of nursing. Nevertheless, there is immeasurable benefit in organising such ideas, and the Roy model of adaptation and nursing practice achieves this. Working with her experiences of cancer patients, and a philosophy of human nature that emphasises endeavour and ability to change, Roy developed a model that has achieved widespread acceptance both within her native United States of America, and across the nursing world.

While Roy's adaptation model has been widely welcomed by nurses, there remains a need to understand it as a whole, and in contexts beyond a single culture of clinical circumstance. If the model is to have relevance to the profession it must offer wisdom beyond rehabilitation settings, and to nurses at all levels of practice. Achieving this dual aim, actioning the model, while reserving the right to pass critical evaluation, have been the purposes of this text. In common with its series companions, it sets out to provide a clear and pragmatic guide to nursing theory, and the extent to which it can inform clinical decisions, care negotiation and professional practice in general.

Recently, the vogue for developing 'reflective practice' has tended to overshadow some aspects of such theory. Intuitive expertise, reflection in action, during the process of care planning and delivering, has become a subject for nursing debate. It can be argued that there is less need for a nursing model. If expert care is largely intuitive, circumstantial and trait related, perhaps nursing models cease to offer guidance to practice? On the other hand however, before experts can emerge, it is usually accepted that they need to formulate ways of thinking about clinical problems. There is a need for models to assist learners as they evolve practice that blends theory and experience, in order to judge when and where to break with convention and offer a different approach.

Whether we believe the nurse is largely intuitive or rational and analytic in her approach to care, Roy's model affords one set of 
guidance notes to inspire and prompt flexible attitudes to practice. Offering as it does encouragement to deeper assessment (stimuli and behaviour), a closer professional relationship, and a greater understanding of physiology (regulator functions) and psychology (cognator functions), it remains a thoroughly modern and relevant model with which to practise. However much we may demur at terminology, or debate nursing roles, few would argue about the central place of adaptation during illness. For this reason, if no other, Roy's model retains a central and well-founded place within the nursing curriculum.

Professor Akinsanya, Greg Cox, Carol Crouch and Lucy Fletcher offer a wide-ranging review of the model and apply it to both circumstances of health and illness. They have not been afraid to explore its potential at each stage of the problem-solving process, nor to test its structure and clarity with patients who offer multiple problems. There is a fresh excitement evident as they apply the model, and ample opportunity to measure the link of theory to practice, stretching across the Atlantic, and from hospital to home. Each of the care studies authenticates Roy's theory in action, and retains some expression of the individual practitioner's way of giving care.

It is as if there is a conceptual tool kit, a resource to be drawn upon. Nevertheless, like all reflective practitioners, these nurses have retained the right to make local decisions, based upon experience as well as model guidance. I hope that as you read through the care studies it will become as apparent to you as it was to me using a model effectively and sensitively is what good nursing is all about. There is no need to turn models, concepts or theories into dogma - whether that be adaptation, reflection or caring.

BOB PRICE $S R N, B A, M S c, C e r t E d(F E), A R R C$ Series Editor 
The preparation of this book began during the most challenging period in British nursing education. The implementation of the Project 2000 proposals depended on links being established between Schools of Nursing and higher education. One of the authors, Justus Akinsanya, delivered a professorial inaugural lecture in 1988 in which he argued that nursing education should be fully integrated into higher education rather than remain outside it.

In October 1992, Anglia Polytechnic University duly brought together all schools of nursing and midwifery in mid, west and south Essex into an integrated Faculty of Health and Social Work. The authors had come together two years earlier to plan and develop ideas for this book.

First and foremost, we would like to thank Bob Price, the Series Editor, for his constructive, incisive and sensitive approach to the demands we made on him. He supported us enthusiastically and was always willing to help sort out otherwise seemingly intractable problems during the writing of this book. Kerry Lawrence, of Macmillan Press, regularly reminded us of our deadlines and her patience is warmly acknowledged.

We are grateful to Sister Callista Roy, the originator of the model, for writing the Foreword to the book. The conceptual clarity of her theoretical thinking challenged us to seek to put the model into action. In doing so, we have gained much from colleagues in the Faculty and within clinical areas. We owe a debt of gratitude to the patients and clients whose care needs shaped our thinking in applying the model as described in the book.

Brenda Marlow and Hiedi Yetton helped in manuscript preparation in a number of ways for which we are grateful. Finally, we would like to pay particular tribute and express our gratitude to our families for their support and patience during the long period of preparing the manuscript for publication.

JUSTUS AKINSANYA GREG COX CAROL CROUCH LUCY FLETCHER 